\title{
THE BIOLOGY OF FRACTURE HEALING IN LONG BONES
}

\author{
B. MCKIBBIN
}

From the Department of Traumatic and Orthopaedic Surgery, Cardiff Royal Infirmary

The healing of a fracture is one of the most remarkable of all the repair processes in the body since it results, not in a scar, but in the actual reconstitution of the injured tissue in something very like its original form. It is not to be expected therefore that the mechanisms controlling such a process will be easily elucidated and indeed they involve problems of cellular homeostasis which are among the most fundamental in biology. If it is not quite the "cunning'st pattern of excelling nature" then it is something quite close to it and a great deal of that pattern at present stands unrevealed.

However, this review is primarily concerned with those features which have direct clinical relevance and it is fortunately possible to treat fractures successfully without a complete understanding of the cellular mechanisms involved without at the same time relying entirely on empiricism. A number of factors influence the healing which can be identified from both clinical and experimental work and may be taken into consideration to put treatment on a more rational basis. It is with these observations that we shall be particularly concerned and cellular mechanisms will be discussed only if they appear to have clinical implications.

Such an account must necessarily include details of the healing process as it is modified by contemporary methods of treatment but first it is necessary to consider the events that occur in the healing of a simple fracture in an unsplinted long bone.

\section{CHANGES ASSOCIATED WITH THE HEALING OF A FRACTURE}

These can conveniently be considered as a series of phases which occur in sequence but which of course also overlap to a certain extent.

Immediate reaction (phase of inflammation) Initially there is bleeding from the damaged bone ends and from the associated soft tissues and a clot soon forms between the fragments. The soft parts in the region show the usual changes of acute inflammation with vasodilatation and the exudation of plasma and leucocytes (Wray 1964). Polymorphs, histiocytes and mast cells soon make their appearance and the process of clearing up of the debris begins (Lindholm et al. 1969).
The first evidence of increased cell division is to be found within about eight hours of the injury reaching a maximum in some twenty-four hours. This activity is first seen in the periosteum and tissues immediately around it and at first extends throughout the whole length of the injured bone. However, within a few days this generalised activity declines and eventually becomes confined to the area immediately adjacent to the fracture where it remains above normal levels for several weeks (Tonna and Cronkite 1961).

Perhaps the most significant observation to be made at this stage is that the ends of the broken bones are not themselves participating in this proliferative activity but are in fact dead, as evidenced by the presence of empty osteocyte lacunae which extend for a variable distance away from the fracture. This phenomenon is explicable on the basis of the anatomical arrangements and anastomotic connections of the blood vessels of compact bone (Ham 1930) and its implications are profound. Although it is almost instinctive to think that the ends of broken bone unite directly to one another it is evident that on the contrary they play, at best, only a passive role in what is an essentially bridging process between the more distant regions of living bone (Fig. 1). This concept is fundamental to much of what is to follow.

The role of the periosteum. A long-standing controversy exists as to the osteogenic potential of the periosteum which was heightened by the authoritative statement by MacEwen (1912) that it was nothing more than a limiting membrane and that the cells which were responsible for the production of new bone belonged properly to the surface of the bone. However, Ham and Harris (1971) have pointed out that this issue is largely semantic. The periosteum is now regarded as consisting of at least two layers, the outer fibrous and the inner cambial, and it is only in the latter that the cells in question lie. These are rather insignificant spindleshaped cells which are indistinguishable from normal fibroblasts and have been termed osteoprogenitor cells (Young 1962) to distinguish them from the osteoblasts to which they give rise, since these latter have lost the power of cell division. In fact these cells are to be found on all free bone surfaces, endosteal as well as periosteal, so that when the periosteum is removed the bone is by no means deprived of its osteogenic potential. It would 
seem therefore that although an alternative terminology has prevailed, MacEwen's view of the periosteum as a separate non-osteogenic fibrous layer is less confusing. Nevertheless, it must be borne in mind that when periosteum is stripped from the bone it carries some of these osteogenic cells with it so that if a segment of bone is excised and the periosteal tube remains this may successfully regenerate a new bone (Mulholland and Pritchard 1959; McClements, Templeton and Pritchard 1961).

The development of osteogenic repair tissue

Traditionally the repair process has been described in terms of the organisation of the fracture haematoma. This is invaded by fibrovascular tissue which replaces the clot and lays down the collagen fibres and the matrix which will later become mineralised to form the woven bone of the so-called provisional or primary callus. The most active cell division is to be seen in the vanguard of this invasion, leaving the more mature tissue closer to
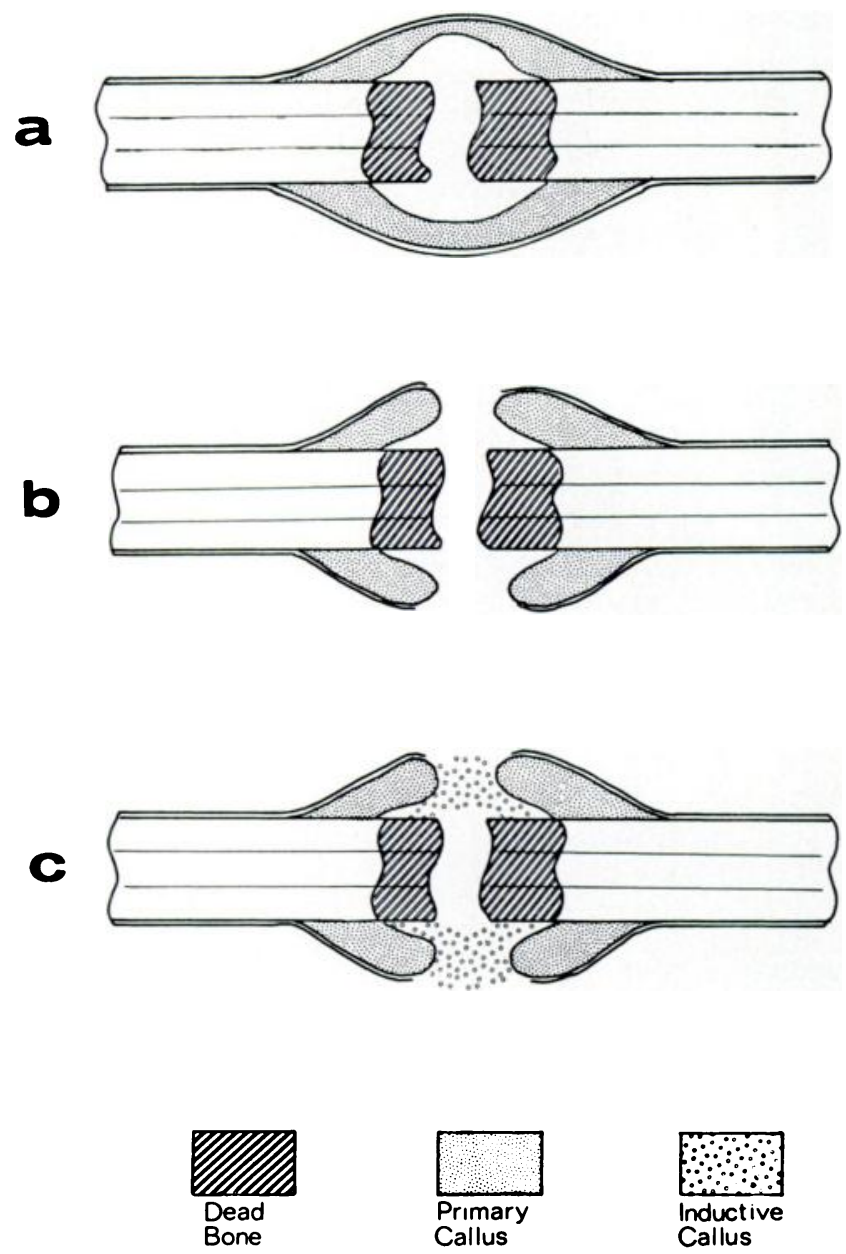

Fig. 1

Diagram illustrating alternative methods of bridging a fracture by external callus. (a) Periosteum intact (Callus bridge). (b) Periosteum discontinuous showing primary callus response. (c) Primary callus response together with bridging external callus formed by induction of the soft tissues.

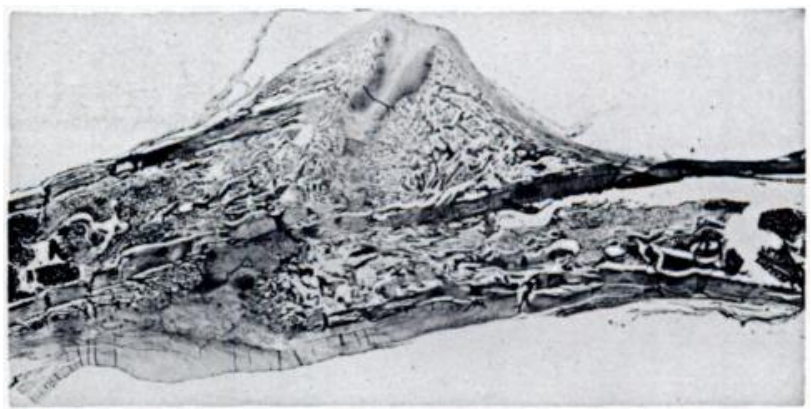

Fig. 2

Unsplinted rib fracture in a sheep at three weeks. Well-developed collars of subperiosteal callus are present and have joined with the medullary callus of the opposite fragment. Note the presence of cartilaginous tissue. (Haematoxylin and eosin, $\times 2$.)

the bone ends to differentiate so that it is in this region that the first bone is seen anchoring the newly formed mass of callus to the fragments (see Fig. 12).

In some areas, particularly at the periphery of the callus, cartilage may have formed which later becomes converted to bone by a front of endochondral ossification which accompanies the arrival of blood vessels. The amount of this cartilage is very variable for a number of reasons. It appears to be more prominent in lower animals (Pritchard and Ruzicka 1950) and where excessive movement is permitted (Roux 1895; Anderson 1965), but Ham originally pointed out in 1930 that the common factor was probably low oxygen tension and that view has now prevailed (Girgis and Pritchard 1958; Bassett and Herrman 1961). It seems that if the callus outgrows its blood supply, cartilage provides a suitable material less demanding of oxygen which temporarily bridges the gap until the blood supply catches up.

In the meantime similar activity has begun in the medullary region although the vascular response is much slower than on the periosteal side (Gothman 1961). The amount of new bone which is formed is very variable and depends on the nature of the bone involved. It is of course the principle method of union in cancellous bone but can also form in predominantly tubular bone. This is particularly marked if the fracture is offset when it may unite with the periosteal callus of the opposite fragment (Fig. 2), and in those circumstances it may be very vigorous.

Some versions of the process differ somewhat from this traditional account. In particular Ham (1969) has questioned the role of the haematoma. He describes a zone of intense cellular activity in the subperiosteal region, resulting in the formation of two encircling collars of callus which appear as wedge-shaped areas on longitudinal section (Fig. 2) and which gradually approach each other until they meet and union is established. This process may well take place external to the haematoma which is thereby bypassed and dealt with later.

Pritchard (1963), on the other hand, has drawn a distinction between the reparative tissue or blastema 
which arises from the outer fibrous layer of the periosteum and that which emanates from the cambial layer and the medullary cavity, which he terms the osteogenic blastema. Normally the osteogenic blastema, being more centrally placed, invades the haematoma and produces the new bone which bridges the fragments, while the more peripheral zones are more fibrous in character and restore the continuity of the periosteum. In some circumstances the fibrous tissue may invade the fracture gap first, in which case the ingrowth of the osteogenic blastema may be halted unless the fibrous tissue is removed or converted to bone in some way (Mulholland and Pritchard 1959). Clearly the factors that influence this latter process are different from, and indeed a good deal more uncertain than, those that affect the direct growth of the osteogenic blastema, and Pritchard saw the elucidation of these different influences as central to the problem of non-union.

As we shall see, many of the differences of emphasis that appear in these various accounts can probably be explained by differences between the particular bone and species studied, or sometimes by the mode of production of the fracture, but a more fundamental argument, which must be dealt with first, arises out of differing concepts of the source of the osteogenic tissue.

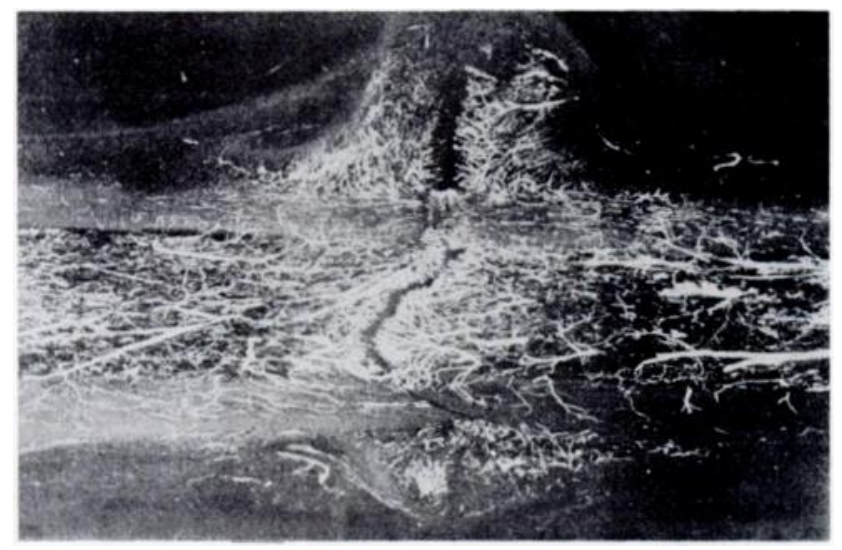

Fig. 3

Blood vessels in external callus originating from the soft tissues. (Reproduced, with permission, from Rhinelander 1974.)

Source of the osteogenic cells. There are two rival theories. According to the first, the repair tissue arises from specialised cells with a predetermined commitment to bone formation. These are the osteoprogenitor cells of which mention has already been made and which occur only in close association with the bone surface or the bone marrow (Owen 1970). As these cells proliferate the fibrous periosteum becomes pushed away from the bone to produce the two advancing collars of callus described by Ham (1969), which eventually fuse with one another.

The alternative view in its most extreme form was originally put forward by Leriche and Policard (1928), who suggested that repair tissue did not arise from specialist cells but rather from the activity of previously uncommitted fibroblasts which could develop the power of osteogenesis if given the appropriate environmental stimulus. Thus the reparative tissue does not arise from the bone itself but from the surrounding soft tissues. This distinction is obviously of considerable practical importance since it elevates the soft tissues to a new key role, while the former theory regards them as being involved only in so far as their damage may be related to interference with the blood supply to the bones themselves.

The phenomenon by which unassociated soft tissues are recruited in this way is known as osteogenic induction. This is a large topic and the reader is referred to the comprehensive reviews by Ostrowski and Wodarski (1971) and Chalmers, Gray and Rush (1975), as well as the classical paper by Urist and McLean (1952). For the present purpose it may be stated that the formation of bone by non-specialised cells in extraskeletal sites is established beyond doubt and many inducing agents both living and non-living have been identified, but what is less certain is whether or not osteogenic induction plays any part in the healing of a fracture.

While it may legitimately be asked for what purpose the induction mechanism does exist if it does not assist in fracture healing, this merely begs the question, and it must be admitted that the only supporting evidence is purely circumstantial.

Fibroblasts in the soft tissues cannot be distinguished morphologically from the osteoprogenitor cells of bone and a clue to their origin is given by a consideration of the vascular changes that accompany fracture healing.

Normally the cortex is supplied largely through the medullary system and the flow is centrifugal, the periosteum at best making only a small arterial contribution to the outer cortex (Brooks 1971). Following a fracture, however, there develops very rapidly an extraosseous blood supply (Rhinelander 1974) derived from the surrounding soft tissues. Although this may help to revascularise any necrotic cortex whose medullary supply has been affected, its main purpose appears to be the supply of external callus (Fig. 3); Rhinelander has pointed out that it is facultative and transitory and in later stages of the process regresses as its function is taken over by the redeveloping medullary system.

It is therefore not difficult to believe that if the vessels of external callus originate outside the bone, so also do the cells themselves. Trueta (1968) adduced a good deal of evidence that such cells did in fact arise from vascular endothelium but a new possibility arises from the work of Friedenstein (1968). It appears that some of the cells with osteogenic potential in marrow may have access to the circulation and it may be these which are responsible for extraskeletal bone formation. 
This is not of course quite the same thing as the metaplasia of cells that are normally part of the soft tissues, but in practice the effect is the same. The new bone arises from the soft tissues surrounding the fracture.

Another suggestive feature is the actual appearance of the developing callus. Although this has been described as the coming together of two distinct fronts of ossification, in reality the changes are very diffuse right across the fracture gap, and while the tissues closest to the bone undoubtedly are more mature, the impression given is of an almost simultaneous process rather like the setting of a jelly (Fig. 4). This impression is also conveyed by the radiological appearances (Fig. 5).

Without attempting to settle the argument one way or the other, however, it should be pointed out that these two theories are by no means incompatible.

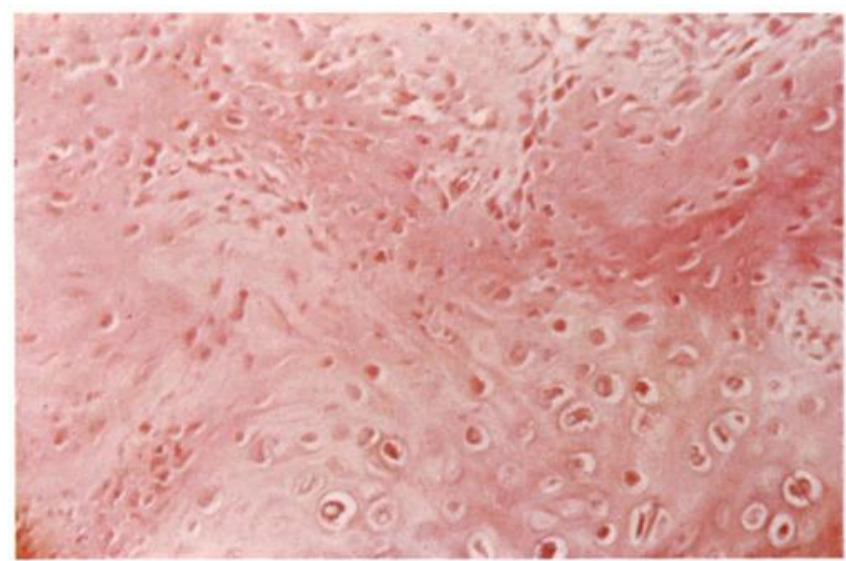

Fig. 4

Part of the callus from a healing rib fracture in a sheep at two weeks. Note the multifocal cellular and osteogenic activity present. (Haematoxylin and eosin, $\times 1000$.)

\section{Phase of remodelling}

Once the fracture has been satisfactorily bridged it is necessary for the newly formed bone to adapt to its new function. This remodelling has also been the subject of considerable study and the reader interested in pursuing this is referred to the reviews of Lacroix and others (Bourne 1971). However, two important points should be emphasised.

First, the process of replacement and repair are going on continuously in the normal skeleton and the mechanisms involved in fracture healing are no different; secondly, there are differences in the process depending on whether it is occurring in compact or cancellous bone. Both essentially involve a process of simultaneous bone removal and replacement through the respective agencies of osteoclasts and osteoblasts together with accompanying blood vessels. In the case of cancellous bone the cells are never very far away from blood vessels and so the whole process of bone apposition or replacement can take place on the surface

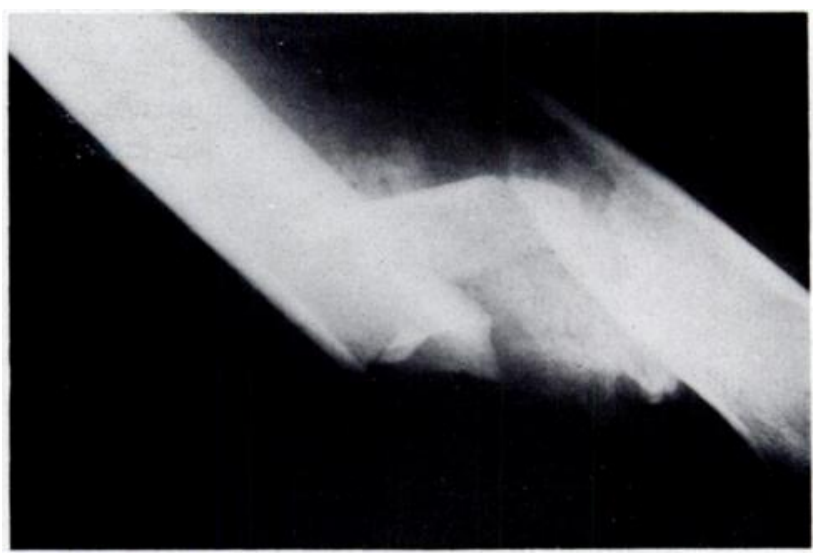

Fig. 5

Radiograph showing pattern of early callus formation in a displaced fracture of the human femur.

of the trabeculae, a phenomenon often referred to as "creeping substitution".

In compact bone, on the other hand, the more deeply placed cells require the presence of Haversian systems which must be replaced, and in these circumstances a more orderly sequence is observed. First, the osteoclasts ream out a tunnel in the dead bone down which a blood vessel follows, bringing the osteoblasts which lay down the lamellar bone of the new osteon (Fig. 6). It may happen that in a fracture the bone ends are so closely opposed that the osteoblastic "cutter head" , as it is sometimes called. may penetrate directly into the opposite fragment, a process which has been referred to as "primary bone union" since no intermediate or precursor cells are involved; this important phenomenon will be dealt with again later.

The fate of the dead bone at the fracture site also requires comment. Although it is commonly believed that this is necessarily resorbed this is by no means always the case, and its fate appears to depend largely on mechanical factors. If normal alignment is preserved then the dead bone will form an important mechanical link in the restoration of continuity and an effort will be made to preserve it in accordance with the workings of

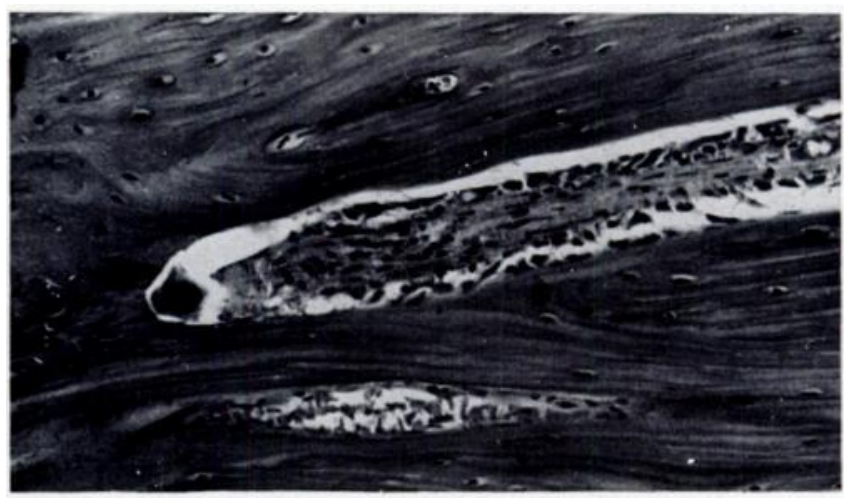

Fig. 6

Formation of new Haversian system in normal cortical bone. (Haematoxylin and eosin, $\times 25$.) 
Wolff s law. Ham (1969) has pointed out that this dead bone may serve as a passive anchorage point for new bony trabeculae and that by the erosion of the dead bone between these, the whole may be converted into living cancellous bone. Alternatively, if the presence of compact bone would be more appropriate then it will be revitalised by the penetration of new Haversian systems in the manner previously described (Schenk and Willinegger 1967). If, on the other hand there is malunion, when incorporation of the bone ends would serve no useful purpose, they then will be completely removed (Fig. 7).

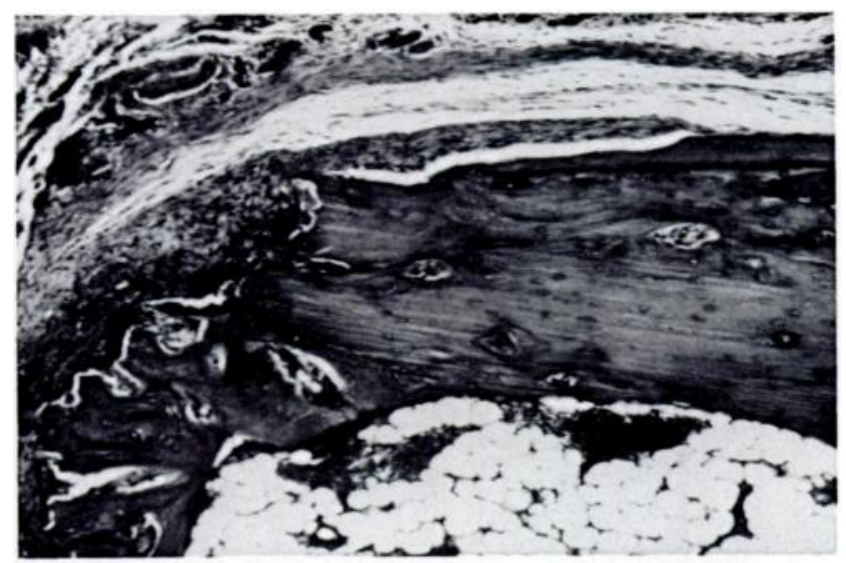

Fig. 7

Dead bone end in displaced fracture undergoing resorption. (Haematoxylin and eosin, $\times 17.5$ approx.)

\section{THE CONTROL OF FRACTURE HEALING}

Charnley (1970) has stressed that in obtaining union of a fracture the critical step is the establishment of an intact bony bridge between the fragments, and since this involves the joining of hard tissue it follows that the whole system must become immobile at least momentarily. Once that bridge has been established, then, provided that adequate mechanical protection is given, subsequent biological failure is unlikely and the other processes such as the hypertrophy of the original bridge and its subsequent remodelling can confidently be expected to follow.

It is appropriate, therefore, to consider the mechanisms that control this initial bridging process. From what has gone before it is apparent that this can come about by one or more of three separate mechanisms, external callus, medullary callus, and the so-called primary bone union. It is proposed therefore to study the mechanisms that influence each of these separately since, as will become apparent, they differ widely.

\section{Healing by external callus}

The first feature that commands our attention in this process is its purposeful nature. Callus does not spread indiscriminately in all directions but tends to orientate itself towards the opposite fragment (Fig. 5). Furthermore, it does not continue to proliferate indefinitely. This is well illustrated by the case of a patient who suffered a tibial fracture on one side while at the same time he sustained a traumatic amputation through the opposite tibia at approximately the same level (Figs. 8 and 9). Six weeks later it can be seen that while the proximal fragment has produced abundant callus on the fractured side, the amputation stump is inert even though it could be regarded as one side of a fracture. Clearly the response of this fragment is in some way dependent on the presence of its fellow.

It is not only the presence of the second fragment that is important, however; we know from clinical experience that the amount of external callus formed is related to the amount of movement present, and the development of methods of more rigid internal fixation has demonstrated that the response can be abolished altogether (Schenk and Willenegger 1967; Anderson 1965). Indeed the exponents of these methods regard the appearance of external callus as evidence of technical failure (Müller, Allgöwer and Willenegger 1965).

The functional purpose of such an arrangement seems very clear. We have two mobile fragments which must be brought to rest before they may be joined together; Charnley (1970) has pointed out how a mass of callus, external to the bone, is mechanically best fitted for this purpose and it is obvious that it should be rapid in its production and purposefully distributed. On the other hand, if that immobilisation is supplied artificially the need for external callus is removed and none will be formed.

These arguments, however appealing, are purely teleological and it is now necessary to enquire into the

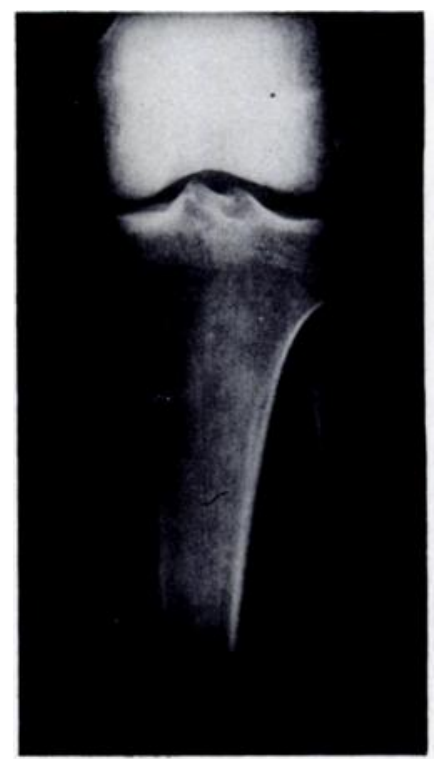

Fig. 8

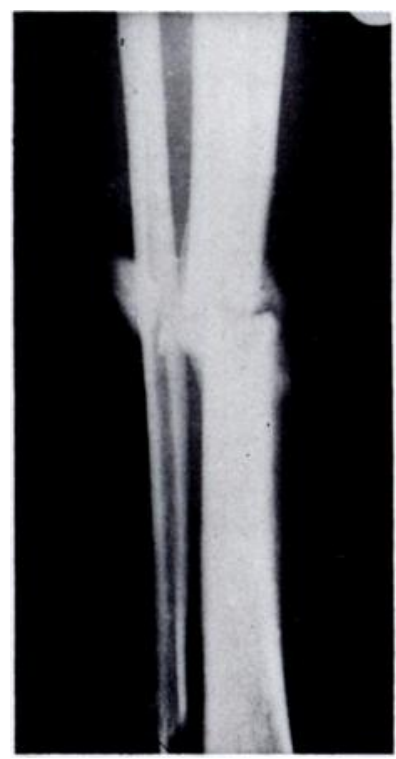

Fig. 9
Figure 8 -The left tibia at six weeks after traumatic amputation. Figure 9-The right tibia sustained a fracture in the same accident. 
actual mechanism by which one fragment exerts its effect upon another. A number of hypotheses will be considered.

Cellular contact theory. If the two fragments remain connected by periosteum or related material it is easy to see how reparative activity could be conducted from one to the other. Such connections have been termed "callus bridges" by Charnley (1970) who has also analysed the situation when they are not present (Fig. 1). Essentially he supports Ham's concept of two advancing collars of callus, which, when they touch, establish cellular continuity between the fragments leading to the establishment of a purposefully orientated bridge which can then be developed. He postulates that if the developing collars are excessively separated, either by distraction or by the interposition of soft tissues or held apart by a long segment of terminal dead bone, then contact cannot occur and non-union will result. Although the theory accounts for a number of clinical observations it is essentially a fatalistic concept, and since it regards all repair tissue as emanating from the bone ends soft tissue interposition must be regarded as insuperable. Most important, however, is its implication that the activity of the callus collars is in some way finite, and that if successful contact is not made they will disappear.

We have already seen that the behaviour of an amputation stump supports this idea and we have found further evidence of this from experiments in our own laboratories. A number of fractures were created which could not possibly unite, either because of the wide gap involved, the presence of interposed tissue or even amputation of the distal fragment (Phillips and McKibbin 1976). In all cases the initial response of the fracture end was identical (Fig. 10). Well-developed callus formed but after two weeks if the collars had made no contact they underwent involution (Fig. 11). Even if any interposed tissue was subsequently removed the periosteum never became reactivated. A similar reaction was seen when the bone was merely injured without producing a complete fracture; and the appearance of an ossifying subperiosteal haematoma is a common clinical entity showing the reaction to be independent of mechanical factors. It would seem, therefore, that when bone is injured it responds in this characteristic way regardless of environmental circumstances but that response is a once-only phenomenon which is limited in duration. This process will be referred to as the primary callus response.

It may well be that in certain favourable circumstances the coming together of these proliferative zones is all that is required to produce union, but the independence of the reaction makes it impossible to explain the effect of the mechanical and other environmental influences; there must, therefore, be a subsequent stage in the process which is susceptible to these influences. This has been termed the phase of external bridging callus (Fig. 12) and it is during this that the participation of induction mechanisms seem most likely (Fig. 1c). Since the factors that are known to influence the induction process include mechanical and humoral agencies, both these require separate consideration.

Mechanical influences (bioelectrical phenomena). Experiments in tissue culture show that differentiation of fibroblasts can be influenced by mechanical factors (Bassett and Herrman 1961) but there is a growing body of evidence to suggest that this form of induction works through the medium of bioelectrical forces. Work in this field was stimulated by the observation by Fukada and Yasuda in 1957 that mechanical deformation of bone gave rise to electrical potentials. These were thought to arise as a result of the piezo-electric effect, although this has nothing to do with the mineral crystals of bone, which are not active in this way, but is due to the collagen itself. Since piezo-electric effects are normally reversible it was inevitable that the effect of electrical influences directly applied to bone should be studied, and it now appears to be indisputable that electronegativity favours bone formation and vice versa (Bassett, Pawluk and Becker 1964). Such a conjunction of observations naturally suggests an hypothesis whereby Wolff's law is explained as a self-regulating feedback mechanism where the appearance of stresses and strains in the bone modifies the electrical environment of the bone cells in such a way as to modify their behaviour (Bassett and Becker 1962). The establishment of proof of such an hypothesis is no easy matter, and as this promising field has developed it has become evident that the electrical environment of bone is extremely complex and that piezo-electrical potentials are only a part of it. Resting potentials were identified by Friedenberg and Brighton (1966) who found that when a bone was fractured the broken ends became more electronegative and therefore possibly associated with increased osteogenesis. However, later workers (Lokietek, Pawluk and Bassett 1974) suggested that these potentials arose from injured tissues and were largely artefactual.

From this point on the subject begins to take on a new dimension of complexity: the reader will learn of the effect of streaming potentials due to the circulation, while electret and pyroelectrical effects and the possible role of semiconductor mechanisms add to the confusion. Promising as this field may be there is obviously a great deal of work still to be done to separate important phenomena from artefact and to convert hypothesis into fact. No attempt will be made to take this any further for the present, and the reader is referred to the comprehensive review by Bassett (1971) as a starting point for further study.

The importance of the subject is reflected by the fact that, prompted by these theories, attempts have already been made to treat human fractures by applying electrical stimuli either in the form of directly applied currents (Friedenberg, Harlow and Brighton 1971) or 
by the non-invasive use of electromagnetic fields (Bassett et al. 1974). Since the selection of these stimuli has necessarily been arbitrary the results must be assessed, as in any other empirical method, by clinical criteria, and such an analysis is outside the scope of this paper. It should be recalled, however, that fracture bridging is a purposeful process and an increase in osteogenesis of itself does not necessarily imply clinical success.

Humoral theories. The role of mechanical factors is obviously important in the induction phase of callus formation but this cannot be regarded as the only stimulus since it does not account for two facts: attempts to bridge the fracture by external callus are not callus (Church and Young 1965) so that if a humoral substance is involved at all in the formation of external callus it must presumably be liberated, not from the injured bone itself, but rather from the products of the primary response. Since we know that this latter is unaffected by mechanical factors and is subject to temporal limitations, this would satisfactorily explain the failure of prolonged mobility to continue the inductive process. It would also account for the rapid and almost simultaneous differentiation which occurs right across the fracture gap in the early phases of successful healing.

Although we have considered a number of hypothesis none of these are mutually exclusive and

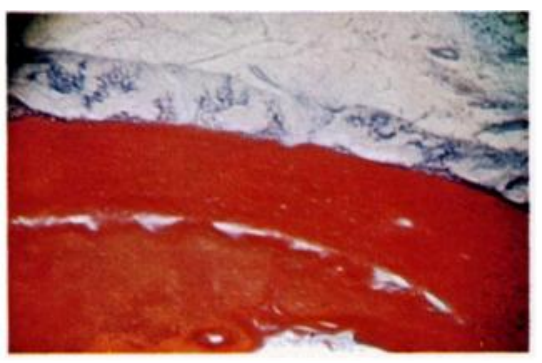

Fig. 10

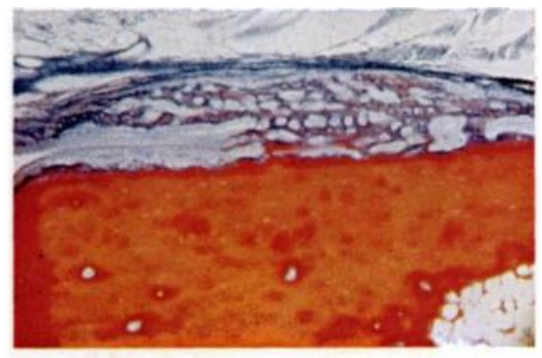

Fig. 11

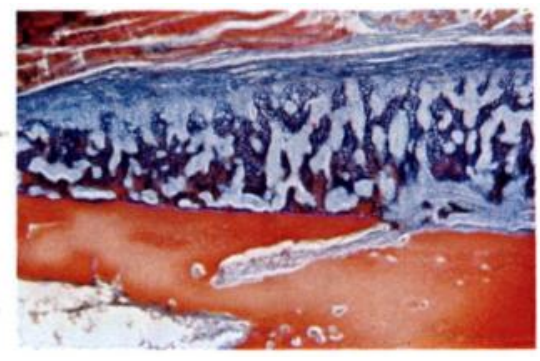

Fig. 12

Development and regression of subperiosteal callus in rat metatarsals. (Ráliß̌ Tetrachrome for osteoid and bone, $\times 50$.) Figure 10-Amputation stump at nine days showing the "primary callus" response. New woven bone is coloured blue. Figure 11-Amputation stump at seventeen days. Involution of the primary callus response has begun. Figure 12-Uniting fracture at seventeen days. Callus formation has progressed leading to formation of "bridging external callus".

prolonged indefinitely, and the continued mobility of a fracture is no guarantee of a continued callus response. The result may be a local activity around the bone end, as in the familiar "elephant foot" radiographic appearance, but the cells between the fragments may fail to respond and bridging may not result. One explanation may be that offered by Pritchard (1963) that the space has now been invaded by non-ossifiable mature fibrous tissue, but it could also be explained by the necessity for some humoral inducing agent which is normally present only for a limited period.

The possibility that fractured bone ends might liberate an agent which influences the healing process was suggested as early as 1920 by Bier. Since then the search for this elusive "wound hormone" has continued, especially in fracture haematoma (Pritchard 1961; Urist and McLean 1952)-but so far without success. Nevertheless, in view of the fact that heterotopic bone formation can be induced by dead tissue and even by bone transplants separated from the host by a millipore membrane (Goldhaber 1961), it seems inevitable that a humoral inducing agent must exist although probably it is effective only under very specific circumstances. Thus Moss (1960) was able to produce bone formation in the skull of young rats with an extract of bovine bone absorbed by Gelfoam. The exclusion of bone ends by Silastic caps does not affect the formation of external since each enjoys a measure of support it seems reasonable to join them together. If the formation of external callus can be considered as two separate but interrelated phases many of the difficulties disappear. Thus there is an initial primary callus response which is largely independent of environmental circumstances and which almost certainly arises from predetermined cells in the bone tissues themselves. This may lead to the subsequent phase of bridging callus formation the speed of which seems likely to depend on the recruitment of cells from the surrounding tissues by a process of induction. It is this phase of the process which is most susceptible to environmental influences particularly with regard to the mutual relationship and movement of the fragments.

\section{Medullary callus}

In many accounts of healing in long bones medullary callus is distinguished from external callus only by its location although it has often been observed that cartilage formation is much less prominent in medullary callus. Nevertheless it appears to be assumed that it is governed by the same influences. This may well be true in the early stages of the healing process and we have seen how in a displaced fracture it may unite directly with external callus (Fig. 2). The reaction in these circumstances is very like that of the primary callus 


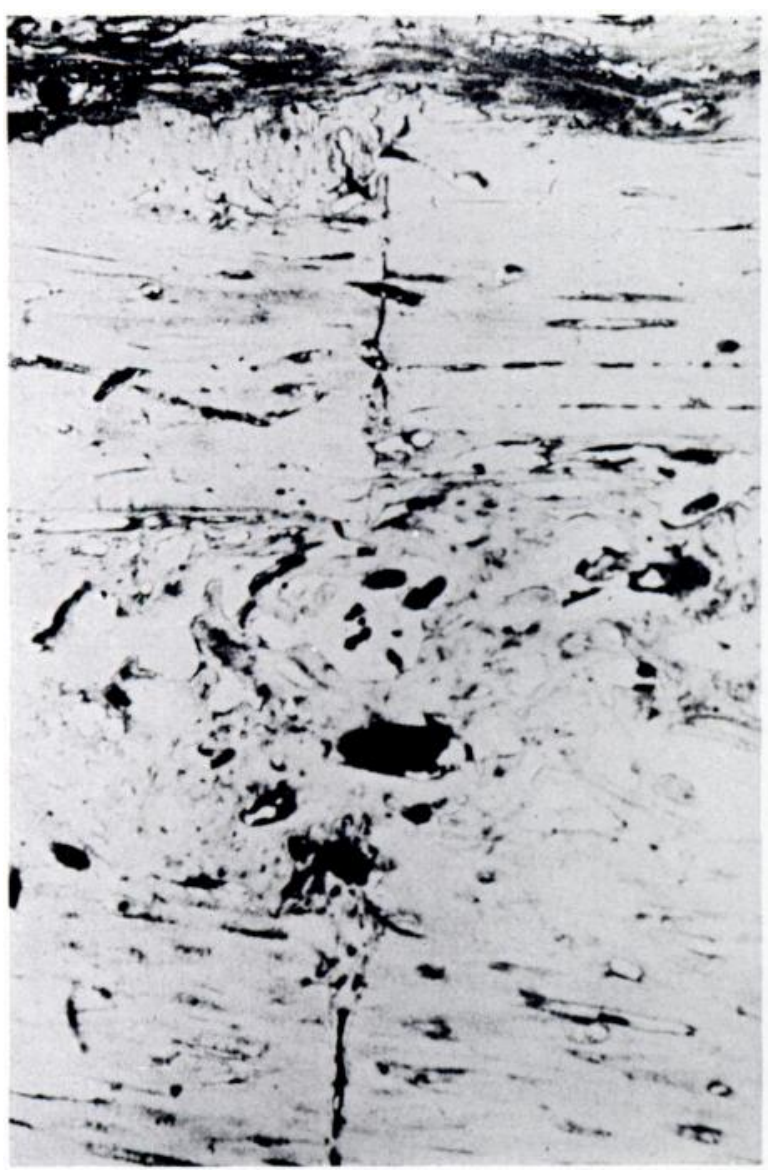

Fig. 13

Formation of medullary callus in a fracture immobilised by compression plating. (Reproduced, with permission, from Rhinelander 1974.)

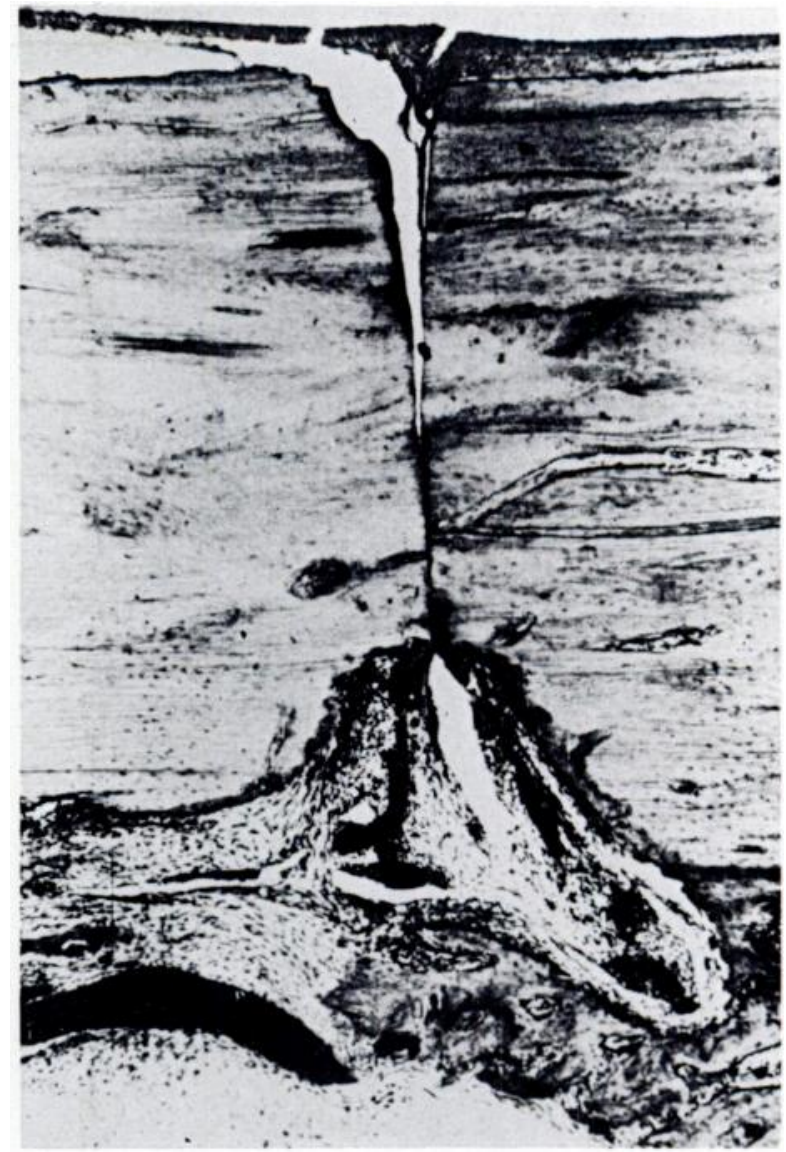

Fig. 14

Fracture immobilised by compression plating showing bridging of the fragments by a "cutter head" and the filling of a non-contact area by medullary bone. (Reproduced. with permission, from Rhinelander 1974.)

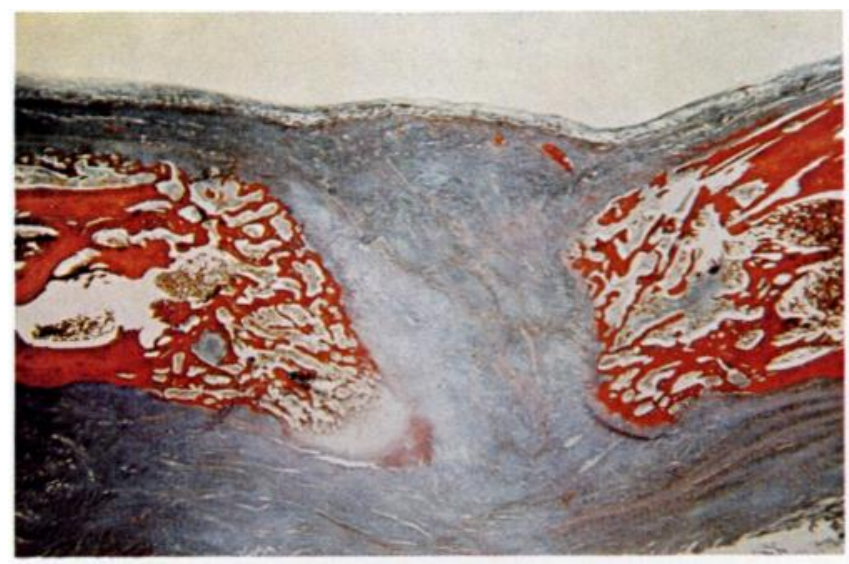

Fig. 15

Rib fracture in sheep with excision of a bone segment at four weeks. The advance of medullary callus into the organised fibrous tissue provides a clear-cut line of demarcation. Compare with Figure 4. (Rálił Tetrachrome for osteoid and bone. $\times 1.5$.) 
response of external callus but it seems that just as a second stage could be identified in that process so also is it the case with medullary callus except that it appears rather later in the healing process and the controlling factors involved appear to be quite different.

The most obvious difference is the effect of mechanical stability. Although this has an inhibitory effect on external callus, medullary callus is unaffected and often flourishes under these conditions (Fig. 13). In intrinsically stable situations such as the healing of a burr hole it is almost the sole method of repair (Johnson 1927) while in fractures immobilised by rigid plating it is often the earliest type of union (Rhinelander 1974; Olerud and Dankwardt-Lillieström 1971). In these circumstances it appears to form without any intermediary stage of fibrocartilage. One of its important functions is to act as a replacing tissue; by filling up any gaps in the fracture line with new woven bone it prepares the way for the subsequent passage of new osteons from one fragment to the other (Fig. 14).

At the same time it is obviously not dependent on total immobility and it can be seen in a rather different form in the later stages of the healing of an unsplinted fracture where there is a large gap (Fig. 15). By this time the external callus response has failed in its purpose and faded away, leaving a well-defined ossifying front clearly distinguishable from the fibrous tissue it is invading and quite unlike the much more diffuse activity of the earlier external callus. This now corresponds very well with the "osteogenic blastema" described by Pritchard (1963). Although the term "medullary callus" is not ideal to describe it since at least some of the activity comes from the external surface of the bone, the term is preferred for the present purpose because it is largely a central activity and it serves to sharpen the many distinctions between it and the earlier external bridging callus.

The appearances suggest much more strongly than with external callus that the osteogenic material is springing from the bone ends themselves and it has been shown in the adult rat that the ability to bridge a fracture gap is greatly diminished if these are lightly cauterised (Mulholland and Pritchard 1959; Templeton 1960). At this stage of the process the activity of the surrounding soft tissue, far from being helpful, may actually interfere with the bridging process by interposing fibrous tissue, and if this can be excluded by joining the fracture ends with a polythene tube much greater gaps can be bridged (Mulholland and Pritchard 1959).

Nevertheless as Pritchard (1963) has pointed out, even where there is fibrous tissue interposition union may sometimes occur by a slow process of replacement, as appears to be happening in Figure 15. This indicates another important difference from external callus in that the process is not an evanescent burst of activity but can continue slowly and relentlessly for months in pursuit of its goal.

Unfortunately we have very little idea about what are the stimuli responsible for the long-continued activity of this type of callus, which can by no means always be relied on. Mechanical factors are obviously not so important as in external callus and the sustained production of a humoral agent for so long seems unlikely. The presence of the opposite fragment is obviously essential since such prolonged activity does not occur in amputation stumps.

Once again, electrical phenomena, probably of the non-mechanically generated type, seems the most likely explanation but biochemical and even neurological mechanisms may be involved. It would seem that this is a part of the fracture healing process which has been inadequately studied as a separate entity.

\section{Primary bone healing}

From the account which has been given of the mode of healing of an unsplinted fracture the idea that direct union between the bone ends may be achieved without the assistance of bridging external callus appears to be illogical. Charnley (1970) believed that there was confusion with the situation in cancellous bone where terminal bone death is minimal and union occurs largely by the process of creeping substitution. Nevertheless, the fact that clinical experience shows the process to be an indisputable reality means that the scientific basis for it must be reappraised.

The explanation was provided by the experiments of Schenk and Willinegger (1967) in which rigid compression plates were applied to the dog's radius. They found that, contrary to expectation, the dead ends of the cortical bone were not resorbed but were recanalised by new Haversian systems in the manner already described, and where the fragments were in direct contact these systems actually crossed from one fragment into the other. In those areas where there were small gaps on the opposite side from the plate the space became filled by what they believed to be new bone arising from the endosteum of the Haversian system. This bone then provided the necessary bridge to conduct new Haversian systems across the gap (Fig. 14). These findings have since been confirmed by others (Olerud and Dankwardt-Lillieström 1968; Rhinelander 1974; Anderson 1965). There does therefore appear to be a third method of fracture bridging whose relationship to mechanical factors is different again from the other two. Obviously the process is not inhibited by stability, as in external callus, and indeed even small degrees of movement are inimical to the process, unlike medullary callus.

This difference is relatively easily explained. It has already been pointed out that the process is nothing more than the mechanism of bone turnover which is occurring all the time in the normal skeleton and there is no reason why it should be inhibited by lack of movement. On the contrary, Schenk and Willinegger (1967) believed that the process was actually speeded up 
because of the need to replace the dead bone which inevitably resulted from the fracture, but subsequent work has not shown this supposition to be correct.

In the first place it seems that the very strength of the fixation deprives the bone of the normal stresses which maintain it and the net result may be an excess of osteoclastic activity leading to some degree of atrophy of the bone (Uhthoff and Dubuc 1971; Tonino et al. 1976). Furthermore in the experiments described the circumstances were rather artificial: the fractures were produced carefully with a fine saw and the amount of bone necrosis was minimal. A more realistic model was constructed by Olerud and Dankwardt-Lillieström (1971) who produced a segmental fracture, and after ensuring that the middle fragment was entirely devoid of vascular connections fixed the whole with a compression plate as rigidly as possible. They found, as did Schenk and Willinegger (1967), that the dead bone did not reduced to a minimum and the mechanical stability is enhanced, but the question arises as to whether there is any direct biological effect due to the compression itself.

At first it was feared that compression might lead to bone necrosis and further resorption but this has been found not to be so by Perren et al. (1969). Bassett and Herrman (1961) showed that in tissue culture fibroblasts could be induced to form bone under conditions of compression, provided a high oxygen level was maintained, while tension resulted in fibrous tissue. Bassett and Becker (1962) did not think this was related to the clinical effects of compression but did not say why. It seems unlikely that such mechanically induced metaplasia would play much part in the healing of a fresh fracture because of the blood supply to such cells is likely to be inadequate, but it could conceivably be important when compression is applied for the treatment of established fibrous union. The problem is worth

Table I. Characteristics of the different healıng processes

\begin{tabular}{|l|c|c|c|c|c|}
\hline \multicolumn{1}{|c|}{ Type of healing } & Speed & $\begin{array}{c}\text { Ability to } \\
\text { bridge gaps }\end{array}$ & $\begin{array}{c}\text { Tolerance of } \\
\text { movement }\end{array}$ & $\begin{array}{c}\text { Tolerance of } \\
\text { total rigidity }\end{array}$ & $\begin{array}{c}\text { Importance of } \\
\text { external soft tissues }\end{array}$ \\
\hline Primary callus response & ++++ & + & ++++ & ++++ & - \\
External bridging callus & +++ & +++ & +++ & - & +++ \\
Late medullary callus & ++ & $\begin{array}{c}++++ \\
\text { (slow) }\end{array}$ & ++ & +++ & - \\
Primary cortical & + & - & - & ++++ & - \\
\hline
\end{tabular}

disappear but was invaded by new osteons from the neighbouring live bone. However, because of the much larger amount of dead bone involved, this process was extremely slow and most of the revascularisation occurred from vessels lying in the medullary canal. Because of the delay, any gaps between the fragments were filled with new bone formed from vessels which did not arise from Haversian canals but which invaded from the periosteum and to a greater extent from the medulla. They pointed out that the orientation of this bone was predominantly parallel to the fracture line and new osteons in the axis of the shaft developed only very much later. It would appear, therefore, that where there is extensive bone necrosis the rebuilding process will be very slow indeed and the patient will be dependent on his implant for a very long time. The radiological obliteration of the fracture gap does not necessarily mean that the bone has returned to its pre-injury strength and indeed it may be doubted whether this is ever the case while rigid fixation remains.

In practice most methods of treatment which seek to achieve direct bone union employ the use of the compression methods which have been developed by the Swiss school (Muller et al. 1965). In the eyes of most surgeons these are effective because the fracture gap is resolving since if the mechanism does not operate it might be more logical to advise the removal of interposed fibrous tissue to facilitate direct osteonal penetration between the bone ends, avoiding the slow alternative process of replacement by woven bone and subsequent remodelling.

\section{SUMMARY OF THE HEALING PROCESS}

It will have become apparent that although this topic is beset with many apparently conflicting descriptions and hypotheses many of these can be resolved by considering the process, not as a single entity but rather as a series of processes each of which is controlled in a different way by environmental circumstances. These are summarised in Table $\mathbf{I}$.

Thus in the first days and weeks there develops what has been termed the primary callus response which appears to be a very fundamental reaction of bone to injury which is almost independent of environmental circumstances. However, it is short-lived and if contact is not soon made with another fragment it will peter out. It seems almost certain that the cells responsible for this activity arise from the bony tissues themselves.

Because this initial response is finite, bridging of the fragments may not result from its activity alone and we 
then enter the phase of bridging external callus. This is a rapid process involving widespread cellular activity between the fragments, and although conclusive proof is lacking there is strong circumstantial evidence to suggest that much of this arises by a process of induction in cells which do not have a direct connection with the bone. Certainly its blood supply arises from the surrounding soft tissues which therefore play a vital role at this stage. This part of the process is very dependent on mechanical factors and may be suppressed by rigid immobilisation. This suggests that its primary purpose is the arrest of movement between the fragments, and there is strong evidence to suggest that this is brought about by a bioelectrical feedback mechanism. Like the primary callus response this activity will not continue indefinitely unless the fracture is bridged, suggesting that it is linked to this earlier process possibly through the intermediary of a humoral agent.

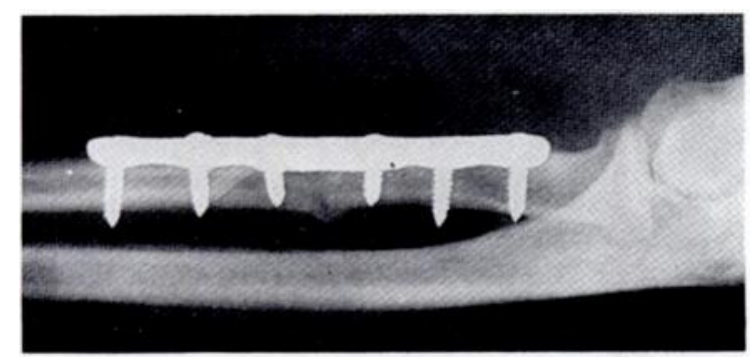

Fig. 16

Fractured radius soundly united following the use of non-rigid fixation. (Reproduced, with permission, from Burwell and Charnley 1964.)

If satisfactory bridging of the fragments is achieved movement is arrested and the remodelling process can then proceed. Unwanted bone, dead or alive, is removed but dead bone whose continued presence would be relevant to the final architectural requirement will be revitalised either by creeping substitution or by the penetration of new Haversian systems according to whether it is of the cancellous or compact type.

Another type of bone formation which appears at this stage has been referred to as late medullary callus since it arises principally but not exclusively from that cavity. It has two special properties in that it is relatively independent of mechanical influences and can replace fibrous tissue by new bone. This latter process is probably necessary in every fracture to facilitate the passage of new ostcons across small gaps, but where the gap is large and the external callus has failed it may still be capable of uniting the ends on its own by the slow replacement of fibrous tissue. The factors that govern this uncertain process are at present unknown but success would seem unlikely without some degree of artificially imposed stability.

If the fracture is treated under circumstances of extreme mechanical rigidity then the process becomes profoundly altered. External bridging callus is suppressed and the healing is dependent on the activity of medullary callus and direct osteonal penetration. There is no evidence to suggest that this process is speeded up in any way when compared with the situation where immobility is achieved naturally by external callus formation and indeed the contrary seems likely. Where there is a large amount of dead bone involved the process may be very protracted indeed.

\section{CLINICAL IMPLICATIONS}

We have seen that there are three main ways in which the essential initial bridging process of fracture healing can come about and how each of these is differently affected by environmental circumstances. Although it is likely that all these processes are involved to a greater or lesser extent in the healing of every fracture the special circumstances imposed by particular methods of clinical management usually means that one or other of them will preponderate. This being so, it would appear wise to plan the treatment consistently so that the predominant mechanism is facilitated or, perhaps more important, not interfered with. This principle may be illustrated using examples of each of the three mechanisms.

External callus. This is the most rapid of all the processes which have been described and is the one which normally predominates in fractures treated by external fixation. This speed is its greatest advantage and there can be no doubt from clinical evidence that this process is the quickest way to restore the strength of a fractured diaphysis to its former level. It is not therefore a process whose inhibition should be considered lightly. It is not necessarily incompatible with internal fixation provided that this does not impose conditions of total rigidity but even then there are important biological considerations to bear in mind.

If plates are to be introduced careful consideration must be given to the soft tissues from which much of the repair tissue will spring and in particular to blood vessels which pass from the muscles and fascia to the periosteum. If these are stripped completely by extraperiosteal dissection then the formation of callus may be inhibited altogether (Trueta 1968), whereas if the exposure of the bone is produced subperiosteally then these important connections are preserved, facilitating the production of a cuff of subperiosteal callus. It should be stressed that these considerations are quite different from those that apply when rigid plating is contemplated: external callus has then been deliberately abandoned and it is the blood supply of the bone that then becomes paramount. If intramedullary fixation is to be used then even more care is required with the soft tissue. Almost certainly the medullary circulation will have been interrupted at least temporarily and all therefore depends on this alternative source of blood vessels. 
Late medullary callus. This method will predominate when the external callus response has failed. It appears to be assisted by immobilisation but since it will inevitably be a slow process secure internal fixation would appear to be most appropriate. If compression is to be used then the only unanswered question is whether the process can be speeded by the removal of the intervening fibrous tissue or whether the compression can be relied on to induce it to form bone, in which case it can be left in place. This problem is worthy of further study.

Primary bone union. The overwhelming disadvantage of this method is its great slowness. It is not really a method of union at all but a remodelling process which normally occurs very late in the normal healing process, and therefore artificial stability must be maintained for many months and even years. Further delay is provided by the fact that new osteons cannot cross gaps in fibrous tissue and must await their preliminary replacement by medullary callus. Where there are larger gaps it would seem wise to supply that bridge with a bone graft but there seems little point in applying cancellous grafts external to the bone. This is normally done in order to facilitate the formation of external callus and it is scarcely logical to apply it in a situation where that reaction has been deliberately inhibited.

The advantages of having the free use of the rigidly fixed injured limb are nevertheless very great and looking to the future it would seem that the ideal to be pursued would be a system of secure internal fixation, which at the same time did not sacrifice the rapid assistance provided by external callus in the interests of earlier consolidation. The radius illustrated in Figure 16 may represent a technical failure in the eyes of some because of the presence of external callus but it may be doubted if the patient saw it in that light.

Possibly this ideal can be achieved only by devising fixation which can preserve security without necessarily imposing total rigidity. As we have seen, however, there are probably many other ways in which external callus is controlled and we may learn to manipulate some of these to our advantage to produce the same objective.

\section{REFERENCES}

Anderson, L. D. (1965) Compression plate fixation and the effect of different types of internal fixation on fracture healing. Journal of Bone and Joint Surgery, 47-A, 191-208.

Bassett, C. A. L. (1971) Biophysical principles affecting bone structure. In The Biochemistry and Physiology of Bone. Second edition. Vol. 3. Development and Growth, pp. 1-76. Edited by G. H. Bourne. New York and London: Academic Press.

Bassett, C. A. L., and Becker, R. O. (1962) Generation of electric potentials by bone in response to mechanical stress. Science, 137, $1063-1064$.

Bassett, C. A. L., and Herrman, I. (1961) Influence of oxygen concentration and mechnical factors on differentiation of connective tissue in vitro. Nature, 190, 460-461.

Bassett, C. A. L., Pawluk, R. J., and Becker, R. O. (1964) Effect of electric currents on bone in vivo. Nuture, 204, 652-654.

Bassett, C. A. L., Pawluk, R. J., and Pilla, A. A. (1974) Acceleration of fracture repair by electromagnetic fields: a surgically non-invasive method. Annals of the New York Academy of Sciences, 238, 242-261.

Bier, H. (1920) Experimentelle Erfahrungen über Pseudarthrosenbildung. Münchener medizinische Wochenschrifi, 67, 22.

Bourne, G. H. (1971) The Biochemistry and Physiology of Bone. Second edition. Vol. 3. Development and Growth. New York and London: Academic Press.

Brookes, M. (1971) The Blood Supply of Bone; An Approach to Bone Biology. London: Butterworths.

Burwell, H. N., and Charnley, A. D. (1964) Treatment of forearm fractures in adults with particular reference to plate fixation. Journal of Bone and Joint Surgery, 46-B, 404-425.

Chalmers, J., Gray, D. H., and Rush, J. (1975) Observations on the induction of bone in soft tissues. Journal of Bone and Joint Surgery: 57-B, 36-45.

Charnley, J. (1970) The Closed Treatment of Common Fractures. Third edition. Edinburgh and London: E. \& S. Livingstone Ltd.

Church, J., and Young, M. H. (1965) Unpublished data.

Friedenberg, Z. B., and Brighton, C. T. (1966) Bioelectrical potentials in bone. Journal of Bone and Joint Surgery, 48-A, 915-923.

Friedenberg, Z. B., Harlow, M. C., and Brighton, C. T. (1971) Healing of nonunion of the medial malleolus by means of direct current: a case report. Journal of Trauma, 11, 883-885.

Friedenstein, A. Y. (1968) Induction of bone tissue by transitional epithelium. Clinical Orthopaedics and Related Research, 59, 21-37.

Fukada, E., and Yasuda, I. (1957) On the piezoelectric effect of bone. Journal of the Physical Society of Japan, 12, 1158-1162.

Girgis, F. G., and Pritchard, J. J. (1958) Experimental production of cartilage during the repair of fractures of the skull vault in rats. Journal of Bone and Joint Surgery, 40-B, 274-281.

Goldhaber, P. (1961) Osteogenic induction across millipore filters in vivo. Science, 133, 2065-2067.

Göthman, L. (1961) Vascular reactions in experimental fractures; microangiographic and radioisotope studies. Acta (hirurgica Scandinavica, Supplement 284.

Ham, A. W. (1930) A histological study of the early phase of bone repair. Journal of Bone and Joint Surgery, 12, 825-844.

Ham, A. W. (1969) Histology. Sixth edition. Philadelphia and Toronto: J. P. Lippincott Co.

Ham, A. W., and Harris, W. R. (1971) Repair and transplantation of bone. In The Biochemistry and Physiology of Bone. Second edition. Vol. 3. Development and Growth, pp. 337-399. Edited by G. H. Bourne. New York and London: Academic Press.

Johnson, R. W., Jun. (1927) A physiological study of the blood supply of the diaphysis. Journal of Bone and Joint Surgery, 9, $153-184$.

Leriche, R., and Policard, A. (1928) The Normal and Pathological Physiology of Bone: Its Problems. Translated by S. Moore and J. A. Key. St Louis: C. V. Mosby Co.

Lindholm, R., Lindholm, S., Liukko, P., Paasimäki, J., Isokääntä, S., Rossi, R., Autio, E., and Tamminen, E. (1969) The mast cell as a component of callus in healing fractures. Journal of Bone and Joint Surgery, 51-B, 148-155.

Lokietek, W., Pawluk, R. J. and Bassett, C. A. L. (1974) Muscle injury potentials; a source of voltage in the undeformed rabbit tibia. Journal of Bone and Joint Surgerv, 56-B, 361-369. 
MacEwen, W. (1912) The Growth of Bone. Glasgow: Maclehose.

McClements, P., Templeton, R. W., and Pritchard, J. J. (1961) Repair of a bone gap. Journal of Anatomy, 95, 616.

Moss, M. L. (1960) Experimental induction of osteogenesis. In Calcification in Biological Systems, pp. 323-348. Edited by R. F. Sognnaes. Washington, D.C.: American Association for the Advancement of Science.

Mulholland, M. C., and Pritchard, J. J. (1959) The fracture gap. Journal of Anatomy, 93, 590.

Müller, M. E., Allgöwer, M., and Willenegger, H. (1965) Technique of Internal Fixation. Berlin, Heidelberg, New York: Springer-Verlag.

Olerud, S., and Dankwardt-Lillieström, G. (1968) Fracture healing in compression osteosynthesis in the dog. Journal of Bone and Joint Surgery, 50-B, 844-851.

Olerud, S., and Dankwardt-Lillieström. G. (1971) Fracture healing in compression osteosynthesis. Acta Orthopacdica Scandinavica, Supplement 137.

Ostrowski, K., and Wodarski, K. (1971) Induction of heterotopic bone formation. In The Biochemistry and Physiology of Bone. Second edition. Vol. 3. Development and Growth, pp. 299-336. Edited by G. H. Bourne, New York and London: Academic Press.

Owen, M. (1970) The origin of hone cells. International Review of Cytology, 28, 213-238.

Perren, S. M., Huggler, A., Russenberger, M., Straumann, F., Müller, M. E., and Allgöwer, M. (1969) A method of measuring the change in compression applied to living cortical bone. Acta Orthopaedica Scandinavica, 125, 5-16.

Phillips, G., and McKibbin, B. (1976) Unpublished data.

Pritchard, J. J. (1961) Hard tissues-bone and bones. In Recent Advances in Anatomy. Second series, pp. 204-236. Edited by F. Goldby and R. J. Harrison. London: J. \& A. Churchill Ltd.

Pritchard, J. J. (1963) Bone healing. The Scientific Basis of Medicine Annual Review's, 286-301.

Pritchard, J. J., and Ruzicka, A. J. (1950) Comparison of fracture repair in the frog, lizard and the rat. Journal of Anatomy, 84, $236-261$.

Rhinelander, F. W. (1974) Tibial blood supply in relation to healing. Clinical Orthopaedics and Related Research, 105, 34-81.

Roux, W. (1895) Gesammelte Abhandluugen über Entwickelungsmechanik der Organismen. Leipzig: W. Englmann.

Schenk, R., and Willenegger, H. (1967) Morphological findings in primary fracture healing. Symposia Biologica Hungarica, 8, 75-86.

Templeton, R. W. (1960) The Mode of Repair of a Fracture Gap. B.Sc. Thesis, Queens University, Belfast (cited by Pritchard, J. J. 1963).

Tonino, A. J., Davidson, C. L., Klopper, P. J., and Linclau, L. A. (1976) Protection from stress in bone and its effects. Journal of Bone and Joint Surgery, 58-B, 107-113.

Tonna, E. A., and Cronkite, E. P. (1961) Cellular response to fracture studied with tritiated thymidine. Journal of Bone and Joint Surgery, 43-A, 352-362.

Trueta, J. (1968) Studies of the Development and Decay of the Human Frame. London: William Heinemann Ltd.

Uhthof, H. K., and Dubuc, F. L. (1971) Bone structure changes in the dog under rigid internal fixation. Clinical Orthopaedics and Related Research, 81, 165-170.

Urist, M. R., and McLean, F. C. (1952) Osteogenetic potency and new-bone formation by induction in transplants to the anterior chamber of the eye. Journal of Bone and Joint Surgery, 34-A, 443-476.

Wray, J. B. (1964) Acute changes in femoral arterial blood flow after closed tibial fracture in dogs. Journal of Bone and Joint Surgery, 46-A, 1262-1268.

Young, R. W. (1962) Cell proliferation and specialization during endochondral osteogenesis in young rats. Journal of Cell Biology, 14, 357-370. 